\title{
Differential $\beta_{3}$ Integrin Expression Regulates the Response of Human Lung and Cardiac Fibroblasts to Extracellular Matrix and Its Components
}

\author{
Nick Merna, MS, Kelsey M. Fung, Jean J. Wang, BS, ${ }^{2}$ Cristi R. King, ${ }^{3}$ Kirk C. Hansen, PhD, ${ }^{4}$ \\ Karen L. Christman, PhD, ${ }^{2}$ and Steven C. George, MD, $\mathrm{PhD}^{3}$
}

Extracellular matrix (ECM) derived from whole organ decellularization has been successfully used in a variety of tissue engineering applications. ECM contains a complex mixture of functional and structural molecules that are ideally suited for the tissue from which the ECM is harvested. However, decellularization disrupts the structural properties and protein composition of the ECM, which may impact function when cells such as the fibroblast are reintroduced during recellularization. We hypothesized that the ECM structure and composition, fibroblast source, and integrin expression would influence the fibroblast phenotype. Human cardiac fibroblasts (HCFs) and normal human lung fibroblasts (NHLFs) were cultured on intact cardiac ECM, collagen gels, and coatings composed of cardiac ECM, lung ECM, and individual ECM components (collagen and fibronectin [FN]) for $48 \mathrm{~h}$. COL1A expression of HCFs and NHLFs cultured on ECM and FN coatings decreased to $<50 \%$ of that of untreated cells; COL1A expression for HCFs cultured on ECM coatings was one- to twofold higher than HCFs cultured on intact ECM. NHLFs cultured on ECM and FN coatings expressed 12- to 31-fold more alpha-smooth muscle actin ( $\alpha$ SMA) than HCFs; the $\alpha$ SMA expression for HCFs and NHLFs cultured on ECM coatings was $\sim 2$ - to 5-fold higher than HCFs and NHLFs cultured on intact ECM. HCFs expressed significantly higher levels of $\beta_{3}$ and $\beta_{4}$ integrins when compared to NHLFs. Inhibition of the $\beta_{3}$ integrin, but not $\beta_{4}$, resulted in a 16- to 26-fold increase in $\alpha$ SMA expression in HCFs cultured on ECM coatings and FN. Our results demonstrate that $\beta_{3}$ integrin expression depends on the source of the fibroblast and that its expression inhibits $\alpha$ SMA expression (and thus the myofibroblast phenotype). We conclude that the fibroblast source and integrin expression play important roles in regulating the fibroblast phenotype.

\section{Introduction}

$\mathbf{E}$ XTRACELlular Matrix (ECM) derived from whole organ decellularization offers a promising biological scaffold for tissue engineering applications. The native structure and biochemical composition of these matrices must be able to support tissue-specific recellularization strategies. However, decellularization protocols use reagents that can disrupt the ECM, resulting in a range of structural properties and protein composition that no longer reflect the ECM in vivo. ${ }^{1}$ Furthermore, the fibroblast phenotype can be organ specific. ${ }^{2}$ Thus, we may be able to improve the decellularization and recellularization process by identifying structural and biochemical features of the ECM that impact organ-specific fibroblast behavior.

Recellularization of decellularized matrices is an intriguing strategy to specifically engineer lung and cardiac tissue ${ }^{3,4}$ that will likely include the fibroblast. The fibroblast is a ubiquitous cell (e.g., it is the most numerous cell type in the heart) that plays a prominent role in the maintenance of tissue architecture through deposition of new, or remodeling of existing, ECM proteins. However, fibroblast cell response to the decellularized matrix remains relatively unexplored. ${ }^{3,5,6}$ Excessive contractile function or collagen deposition induced by abnormal mechanical properties or soluble growth factors could interfere with the normal structure and function of the recellularized tissue. ${ }^{7}$

\footnotetext{
${ }^{1}$ Department of Biomedical Engineering, University of California, Irvine, California.

${ }^{2}$ Department of Bioengineering and Sanford Consortium for Regenerative Medicine, University of California, San Diego, La Jolla, California.

${ }^{3}$ Department of Biomedical Engineering, Washington University in St. Louis, Missouri.

${ }^{4}$ Department of Biochemistry and Molecular Genetics, University of Colorado, Denver, Colorado.
} 
Integrins are membrane-bound proteins that play a critical role in ECM maintenance and remodeling by transmitting signals from the ECM to regulate cell function. In the case of the fibroblast, integrin expression can influence the expression of intracellular structural or contractile proteins, such as alpha-smooth muscle actin ( $\alpha$ SMA $){ }^{8}$ and thus the myofibroblast phenotype, as well as extracellular structural proteins, such as collagen. ${ }^{9}$ However, previous work has not determined the effect of specific decellularized matrix features on fibroblast function and integrin signaling. For example, it is not well understood as to how the collagen microstructure may affect $\alpha$ SMA expression.

Tissue-specific ECM coatings have been shown to provide a culture microenvironment that mimics the in vivo environment and can enhance cell maturation, proliferation, and differentiation. ${ }^{10,11}$ However, ECM coatings can be prepared by pepsin digestion, thus potentially impacting the ultrastructure and response of cells. Intact ECM consists of a mixture of proteins arranged in a three-dimensional pattern that is unique to the tissue from which the ECM is derived. Although intact ECM scaffolds can promote cell functionality and maturation, ${ }^{3,12}$ it is unclear what benefits intact ECM ultrastructure may offer and what impact the altered protein structure in ECM coatings may have on cell response.

Finally, previous studies have shown that the fibroblast source can significantly affect cell morphology and ECM deposition. ${ }^{13}$ Similarly, the ECM has been shown to influence chemotaxis, direct cell differentiation, and induce constructive host tissue remodeling responses. ${ }^{14}$ Nonetheless, it is still unclear whether the fibroblast source or ECM structure and composition both impact the fibroblast phenotype, and what role integrins may play in this process.
The goal of this study is to determine the effect of ECM structure and composition, fibroblast source, and integrin expression on the fibroblast phenotype by seeding human cardiac and lung fibroblasts on cardiac ECM, lung ECM, and individual ECM components. Our results demonstrate that $\beta_{3}$ integrin expression is differentially expressed in fibroblasts of lung and cardiac origin and that its expression inhibits $\alpha$ SMA expression (and thus the myofibroblast phenotype). This result suggests that organ-specific fibroblasts may be an important factor in effective recellularization strategies.

\section{Materials and Methods}

\section{Preparation of ECM}

Whole porcine hearts were obtained immediately after euthanasia of $40-55 \mathrm{~kg}$, adult female Yorkshire pigs. The excess fat and connective tissue were removed, and the coronaries were perfused with phosphate-buffered saline (PBS) to remove coagulated blood. Each heart was frozen at $-80^{\circ} \mathrm{C}$ for at least $24 \mathrm{~h}$ to aid in cell lysis. These hearts were then thawed at room temperature and decellularized over a 7-day period by coronary perfusion with two different solutions of either trypsin/ethylenediaminetetraacetic acid (EDTA)/ $\mathrm{NaN}_{3}$ or Triton/EDTA/NaN 3 (Fisher Scientific), as previously described (Table 1$).^{5}$

Different combinations of trypsin and triton were used as their mechanism of action should differentially impact the ECM. $^{5,15}$ Hearts were treated with the trypsin solution for 1 day, followed by triton solution for 6 days (CECM2). Hearts were also treated with the trypsin solution for 3 days, followed by triton solution for 4 days (CECM3). Full-thickness left ventricular tissue samples $(1 \times 1 \mathrm{~cm})$ were collected after

TABle 1. Conditions

\begin{tabular}{|c|c|}
\hline TGF- $\beta$ & $50 \mathrm{ng} / \mathrm{mL}$ TGF- $\beta$ \\
\hline TNF- $\alpha$ & $100 \mathrm{ng} / \mathrm{mL}$ TNF- $\alpha$ \\
\hline Coll8 coat & $1 \mathrm{mg} / \mathrm{mL}$ type 1 collagen in $0.1 \mathrm{M}$ acetic acid for $1 \mathrm{~h}$ at $37^{\circ} \mathrm{C}$ \\
\hline FN coat & Coated at $25 \mu \mathrm{g} / \mathrm{mL}$ fibronectin for $1 \mathrm{~h}$ at $37^{\circ} \mathrm{C}$ \\
\hline LECM1 coat & $\begin{array}{l}\text { Porcine lung tissue decellularized by } 1 \% \text { sodium dodecyl sulfate for } 4-5 \text { days and rinsed } \\
\text { with deionized water overnight. Then milled into a fine powder, digested in pepsin, } \\
\text { and coated at } 1 \mathrm{mg} / \mathrm{mL} \text { in } 0.1 \mathrm{M} \text { acetic acid for } 1 \mathrm{~h} \text { at } 37^{\circ} \mathrm{C}\end{array}$ \\
\hline CECM1 coat & $\begin{array}{l}\text { Porcine ventricular tissue decellularized by } 1 \% \text { sodium dodecyl sulfate for } 4-5 \text { days } \\
\text { and rinsed with deionized water overnight. Then milled into a fine powder, digested in pepsin, } \\
\text { and coated at } 1 \mathrm{mg} / \mathrm{mL} \text { in } 0.1 \mathrm{M} \text { acetic acid for } 1 \mathrm{~h} \text { at } 37^{\circ} \mathrm{C}\end{array}$ \\
\hline CECM2 coat & $\begin{array}{l}\text { Porcine ventricular tissue decellularized by } 0.02 \% \text { Trypsin/ } / 0.05 \% \text { EDTA/ } 0.05 \% \mathrm{NaN}_{3} \\
\text { for } 1 \text { day and } 3 \% \text { Triton X-100/0.05\% EDTA/ } 0.05 \% \mathrm{NaN}_{3} \text { for } 6 \text { days. Desiccated, reduced } \\
\text { to powder, treated with pepsin for } 4 \text { days, and coated at } 1 \mathrm{mg} / \mathrm{mL} \text { in } 0.1 \mathrm{M} \text { acetic acid } \\
\text { for } 1 \mathrm{~h} \text { at } 37^{\circ} \mathrm{C}\end{array}$ \\
\hline CECM3 coat & $\begin{array}{l}\text { Porcine ventricular tissue decellularized by } 0.02 \% \text { Trypsin } / 0.05 \% \text { EDTA } / 0.05 \% \mathrm{NaN}_{3} \\
\text { for } 3 \text { days and } 3 \% \text { Triton X-100/0.05\% EDTA/0.05\% } \mathrm{NaN}_{3} \text { for } 4 \text { days. Desiccated, reduced } \\
\text { to powder, treated with pepsin for } 4 \text { days, and coated at } 1 \mathrm{mg} / \mathrm{mL} \text { in } 0.1 \mathrm{M} \text { acetic acid } \\
\text { for } 1 \mathrm{~h} \text { at } 37^{\circ} \mathrm{C}\end{array}$ \\
\hline Coll gel & $10 \mathrm{mg} / \mathrm{mL}$ type 1 collagen at $\mathrm{pH} 8.5(2 \mathrm{~mL}$ gel $)$ for $1 \mathrm{~h}$ at $37^{\circ} \mathrm{C}$ \\
\hline CECM1 intact & $\begin{array}{l}\text { Porcine ventricular tissue decellularized by } 002 \% \text { Trypsin } / 0.05 \% \text { EDTA/ } 0.05 \% \mathrm{NaN}_{3} \\
\text { for } 1 \text { day and } 3 \% \text { Triton X-100/0.05\% EDTA/ } 0.05 \% \mathrm{NaN}_{3} \text { for } 6 \text { days }\end{array}$ \\
\hline CECM2 intact & $\begin{array}{l}\text { Porcine ventricular tissue decellularized by } 0.02 \% \text { Trypsin } / 0.05 \% \text { EDTA } / 0.05 \% \mathrm{NaN}_{3} \\
\text { for } 3 \text { days and } 3 \% \text { Triton X-100/0.05\% EDTA } / 0.05 \% \mathrm{NaN}_{3} \text { for } 4 \text { days }\end{array}$ \\
\hline
\end{tabular}

TGF, transforming growth factor; TNF, tumor necrosis factor; EDTA, ethylenediaminetetraacetic acid; FN, fibronectin. 
7 days (CECM2 intact and CECM3 intact). The decellularized C-ECM was then desiccated and reduced to a powder.

One gram of C-ECM powder and $100 \mathrm{mg}$ of pepsin (Sigma; $\sim 2500 \mathrm{U} / \mathrm{mg}$ ) were mixed in $100 \mathrm{~mL}$ of $0.01 \mathrm{M}$ $\mathrm{HCl}$ (Fisher Scientific) for 4 days at room temperature. The resulting solution had a $\mathrm{pH}$ of $\sim 2.8-3.2$. C-ECM coatings were formed by mixing $0.1 \mathrm{M} \mathrm{NaOH}$ (Fisher Scientific) and $1 \times$ PBS (Invitrogen) at $4^{\circ} \mathrm{C}$. The solution was brought to $1 \mathrm{mg} / \mathrm{mL}$ and $\mathrm{pH} 8.5$ and then coated on T-25 flasks for $1 \mathrm{~h}$ at $37^{\circ} \mathrm{C}$ (CECM2 coat and CECM3 coat).

$\mathrm{C}-\mathrm{ECM}$ and L-ECM were also provided by the Christman laboratory and prepared as previously described. ${ }^{16}$ Briefly, porcine ventricular tissue and lung tissue were decellularized using $1 \%$ sodium dodecyl sulfate for $4-5$ days. The decellularized ECM was then rinsed with deionized water overnight and milled into a fine powder. The powder was then digested in pepsin in $0.1 \mathrm{M} \mathrm{HCl}$, adjusted to $\mathrm{pH} 7.4$, and relyophilized for storage at $-80^{\circ} \mathrm{C}$. The material was then rehydrated and brought to $1 \mathrm{mg} / \mathrm{mL}$ and $\mathrm{pH} 8.5$ and then coated on T-25 flasks for $1 \mathrm{~h}$ at $37^{\circ} \mathrm{C}$ (CECM1 coat and LECM1 coat).

\section{Cell culture}

Two lots of human cardiac fibroblasts (HCFs; Lonza), derived from a 42-year-old male (lot 1) and a 44-year-old man (lot 2), and two lots of normal human lung fibroblasts (NHLFs; Lonza), derived from similarly aged donors, were independently seeded at a density of 3500 cells $/ \mathrm{cm}^{2}$ on T-25 tissue culture flasks coated for $1 \mathrm{~h}$ at $37^{\circ} \mathrm{C}$ with $1 \mathrm{mg} / \mathrm{mL}$ type I collagen (coll coat; BD Biosciences), $25 \mu \mathrm{g} / \mathrm{mL}$ fibronectin (FN coat; Life Technologies), $1 \mathrm{mg} / \mathrm{mL} \mathrm{C-ECM}$ (CECM1 coat, CECM2 coat, and CECM3 coat), or $1 \mathrm{mg} / \mathrm{mL}$ L-ECM (LECM1 coat), as well as on T-25 flasks containing $2 \mathrm{~mL}$ collagen gels (coll gel) or intact C-ECM samples (CECM2 intact and CECM3 intact). Collagen gels were formed by bringing $2 \mathrm{~mL}$ of $10 \mathrm{mg} / \mathrm{mL}$ type 1 collagen to $\mathrm{pH}$ 8.5 for $1 \mathrm{~h}$ at $25^{\circ} \mathrm{C}$.

Cells were also seeded on uncoated flasks that were left untreated (by which the data were normalized) or treated with $50 \mathrm{ng} / \mathrm{mL}$ transforming growth factor (TGF) $\beta$ or $100 \mathrm{ng} /$ $\mathrm{mL}$ tumor necrosis factor (TNF) $\alpha(N=3$, Table 2$)$. The profibrotic protein TGF $\beta$ induces fibroblast expression of $\alpha$ SMA and collagen I and was chosen as a positive control. ${ }^{17}$ Conversely, the proinflammatory cytokine, TNF $\alpha$, suppresses expression of $\alpha \mathrm{SMA}$ and collagen I and was chosen as a negative control. ${ }^{18,19}$

\section{RNA quantification}

Total RNA was isolated from HCFs and NHLFs after $48 \mathrm{~h}$ of culture under each condition (Aurum Total RNA Mini Kit and RNAzol; Bio-Rad). RNA quantity and purity were measured using a spectrophotometer (DU 730 Beckman Coulter). cDNA was then synthesized from mRNA (iScript Reverse Transcription Supermix; Bio-Rad). An optimal reference gene was then chosen using a commercially available predesigned plate (Reference Gene H96; Bio-Rad). Collagen I (COL1A, $N=3$, Fig. 2 ), $\alpha$ SMA ( $N=3$, Fig. 2 ), and glucose6-phosphate dehydrogenase (G6PD) RNAs were then quantified by real-time quantitative PCR (PrimePCR SYBR Green Assay; Bio-Rad) using a CFX96 Real-Time PCR Detection System (Bio-Rad).
A standard curve was created for each primer using twofold serially diluted cDNA from untreated HCFs and NHLFs. From these curves, gene expression was determined for each condition relative to untreated cells. The expression of the target genes (COL1A and $\alpha \mathrm{SMA}$ ) was then quantified relative to the housekeeper gene (G6PD) for each condition, to account for differences in cell proliferation.

\section{Cell proliferation and migration assay}

Proliferation rates of NHLFs cultured on LECM1 and HCFs cultured on cardiac CECM1 were determined using the BrdU labeling reagent. Cells were cultured in a 24-well dish and then stained with the TRITC BrdU labeling reagent and counterstained for 4',6-diamidino-2-phenylindole (DAPI) $(N=4)$. BrdU-positive nuclei were visualized, and the percentage of cells in the S-phase was determined by the number of BrdU-positive cells in relation to the total number of cells per image. Statistical significance was determined by a Student's $t$-test.

We employed a simple scratch-wound assay to assess cell migration as previously described. ${ }^{20}$ Scratch wounds were also applied to NHLF and HCF monolayers cultured on LECM1- and CECM1-coated flasks, respectively, similar to the cell proliferation assay $(N=4)$. The separation distance between the edges of the scratch wound was measured at three locations from brightfield images for 10 time points over a 24-h time period. An average wound thickness or distance was then determined (mean of the three measurements) as a function of time.

\section{Characterization of lung and cardiac ECM}

The presence of biochemical cues was assessed using assays for protein and peptide content (sodium dodecyl sulfate-polyacrylamide gel electrophoresis [SDS-PAGE] and mass spectrometry) of the L-ECM and C-ECM. Solubilized LECM1 and CECM1 were run on a NuPAGE $12 \%$ Bis-Tris Gel (Life Technologies) according to the manufacturer's instructions using the MOPS SDS Running Buffer under reducing conditions. Samples were compared to the Amersham ECL Full-Range Rainbow Molecular Weight Markers (GE Healthcare). After electrophoresis, gels were stained with an Imperial Protein Stain (Thermo Scientific) to visualize the bands.

To further characterize the protein content of the lung and cardiac ECM, mass spectrometry was performed. ECM samples were digested using pepsin and analyzed by liquid chromatography (LC)-MS/MS with electrospray ionization. Samples were analyzed on an LTQ Orbitrap Velos mass spectrometer (Thermo Fisher Scientific) coupled to an Eksigent nanoLC-2D system through a nanoelectrospray LC MS interface. Data acquisition was performed using the instrument supplied Xcalibur ${ }^{\mathrm{TM}}$ (version 2.1) software. MS/ MS spectra were extracted from raw data files and converted into mgf files using a PAVA script (UCSF, MSF). These mgf files were then independently searched against the Sus Scrofa database using an in-house Mascot ${ }^{\mathrm{TM}}$ server (version 2.2.06; Matrix Science).

Mass tolerances were $\pm 15 \mathrm{ppm}$ for MS peaks and $\pm 0.6 \mathrm{Da}$ for MS/MS fragment ions. Three different search modes, where cleavage specificity was set to $\mathrm{CNBr} /$ trypsin, 
semitrypsin, or nonenzyme, were used allowing for one missed cleavage. Met oxidation, proline hydroxylation, protein $\mathrm{N}$-terminal acetylation, and peptide $\mathrm{N}$-terminal pyroglutamic acid formation were allowed for variable modifications, while carbamidomethyl of Cys was set as a fixed modification.

The scaffold (version 4.3.2; Proteome Software) was used to validate MS/MS-based peptide and protein identifications. All mascot DAT files, for each subject (six fractions each), were loaded together as one biological sample within the scaffold. Peptide identifications were accepted if they could be established at $>95.0 \%$ probability as specified by the Peptide Prophet algorithm. Protein identifications were accepted if they could be established at $>99.0 \%$ probability and contained at least two identified unique peptides.

\section{Integrin expression quantification}

HCF and NHLF cell suspensions were prepared by rinsing each condition (collagen, L-ECM, C-ECM, and FN coatings) with HBSS and then treating each flask with $0.025 \%$ trypsin in PBS for $4 \mathrm{~min}$. Cells were then resuspended in an assay buffer and added to integrin assay wells at 100,000 cells/well $(N=3$, as per manufacturer's instructions, Alpha/Beta Integrin-Mediated Cell Adhesion Array Combo Kit; Millipore). Each well was used to capture cells expressing particular integrins on their cell surface. Unbound cells were washed away, and adherent cells were fixed and stained. Relative cell attachment was determined using absorbance readings, measured at $540 \mathrm{~nm}$ using a Bio-Rad Benchmark Microplate Reader (Fig. 4).

\section{Functional blocking studies}

In inhibition studies with blocking antibodies $(N=3$, Fig. 5), HCF, and NHLF, cell suspensions were treated with $10 \mu \mathrm{g}$ / $\mathrm{mL}$ of anti- $\beta 3$-integrin (CD61; Millipore) or $10 \mu \mathrm{g} / \mathrm{mL}$ of anti- $\beta 4$-integrin (ASC-8; Millipore) for $30 \mathrm{~min}$ and then seeded on T25 tissue culture flasks as previously described.

\section{¿SMA labeling}

HCFs and NHLFs were labeled with a monoclonal antibody recognizing $\alpha$ SMA followed by Alexa Fluor 488 goat anti-mouse immunoglobulin G (Life Technologies). Samples were counterstained with DAPI to visualize cell nuclei and analyzed using confocal microscopy (Fig. 6) to determine the fraction of $\alpha$ SMA-positive cells.

\section{Mechanical testing}

The compressive modulus of collagen gels and intact C-ECM samples were measured through indentation testing (Synergie 100; MTS Systems Corporation). The sample height $(15 \mathrm{~mm})$ was measured using a linear extensor. Each sample was then compressed to $20 \%$ strain with a 5 -mmradius plate at a rate of $0.02 \mathrm{~mm} / \mathrm{s}$. Data were acquired with a $10 \mathrm{~N}$ load cell at $50 \mathrm{~Hz}$ with a 12-bit data acquisition. The modulus was calculated in the linear region of the stress- strain curve. Each sample was tested in five locations and the values averaged.

\section{Statistical analysis}

The COL1A RNA content, $\alpha$ SMA RNA content, integrin expression, compressive modulus, and promoter reporter fluorescence were analyzed using one-way analysis of variance and post hoc paired $t$-tests. SigmaStat was used to perform the statistical tests, and $p<0.05$ was considered significant.

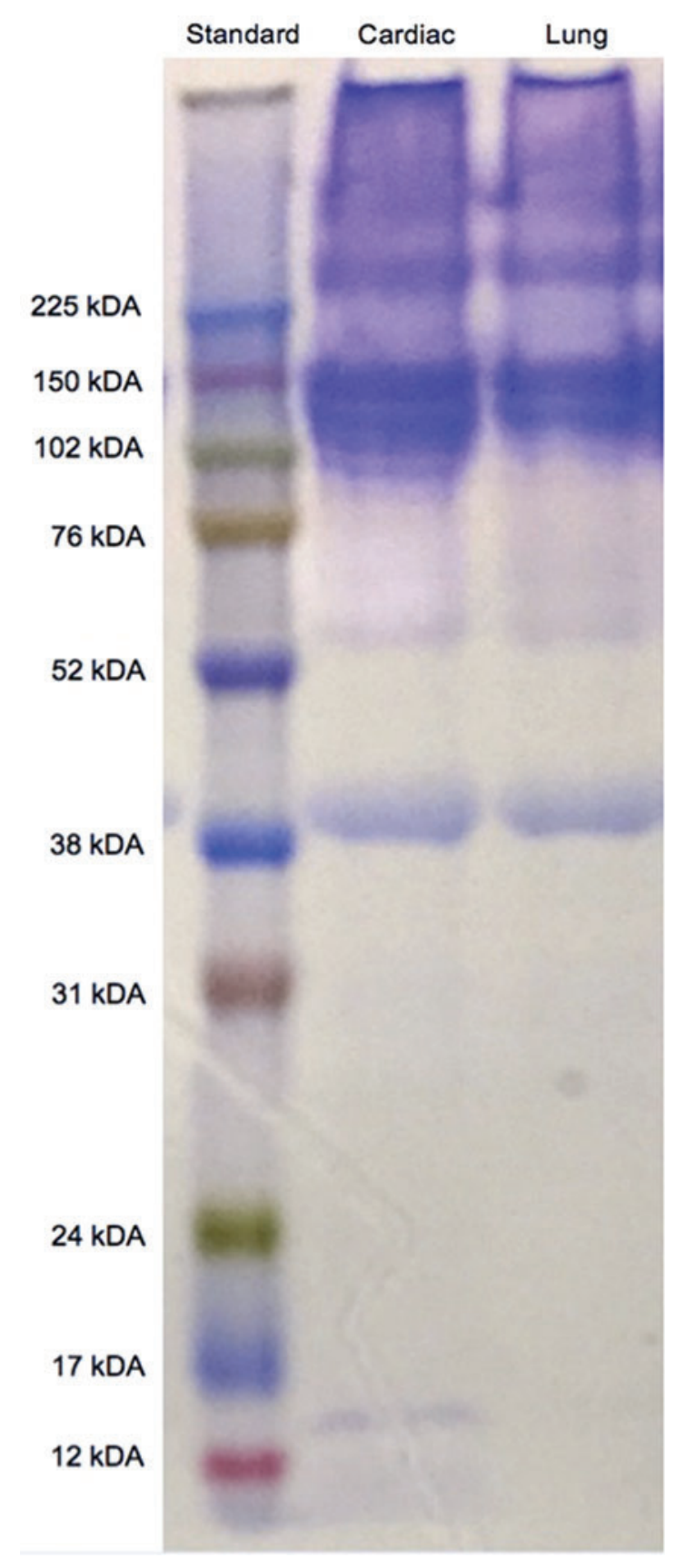

FIG. 1. Sodium dodecyl sulfate-polyacrylamide gel electrophoresis gel of cardiac and lung matrix. The cardiac and lung matrix shows significant overlap in protein bands, with some differences, notably at $\sim 100-120 \mathrm{kDa}$. Color images available online at www.liebertpub.com/tea 
Table 2. Mass Spectrometry Composition Analysis

\begin{tabular}{lcc}
\hline & Lung ECM & Cardiac ECM \\
\hline Collagen I & $\mathrm{X}$ & $\mathrm{X}$ \\
Collagen II & $\mathrm{X}$ & $\mathrm{X}$ \\
Collagen III & $\mathrm{X}$ & $\mathrm{X}$ \\
Collagen IV & $\mathrm{X}$ & $\mathrm{X}$ \\
Collagen V & $\mathrm{X}$ & $\mathrm{X}$ \\
Collagen VI & $\mathrm{X}$ & $\mathrm{X}$ \\
Collagen VII & & $\mathrm{X}$ \\
Collagen VIII & $\mathrm{X}$ & $\mathrm{X}$ \\
Collagen IX & $\mathrm{X}$ & $\mathrm{X}$ \\
Elastin & $\mathrm{X}$ & $\mathrm{X}$ \\
Fibrillin-1 & $\mathrm{X}$ & $\mathrm{X}$ \\
Fibronectin-1 & $\mathrm{X}$ & $\mathrm{X}$ \\
Fibrinogen & & $\mathrm{X}$ \\
Laminin & & \\
HSPG & &
\end{tabular}

$\mathrm{X}$ signifies the presence of a protein.

ECM, extracellular matrix; HSPG, heparan sulfate proteoglycan.

\section{Results}

\section{Structure and composition of ECM}

ECM contains a complex mixture of instructive proteins that are unique to the tissue from which the ECM was harvested. As a first step in comparing cardiac and lung ECM composition, we performed SDS-PAGE. The cardiac and lung ECM demonstrate similar banding patterns with notable differences in the ranges of $12-17 \mathrm{kDa}$ and 100 $120 \mathrm{kDa}$ (Fig. 1). We also performed additional characterization through mass spectrometry to identify the general protein composition (Table 2). Both LECM1 and CECM1 contain collagen I, III, IV, V, VI, and VIII, as well as elastin, fibrillin-1, FN 1, and laminin. The presence of collagen II and IX was unique to LECM1, and the presence of collagen VII, fibrinogen, and heparin sulfate proteoglycans was unique to CECM1.

\section{COL1A RNA content}

Excessive collagen deposition by fibroblasts typifies a myofibroblast phenotype and can impair normal tissue function. To determine if fibroblasts exhibit a fibrotic response to ECM, we measured COL1A expression of HCFs and NHLFs cultured on C-ECM, L-ECM, and individual ECM components for $48 \mathrm{~h}$. The most striking result was that culture of HCFs and NHLFs on ECM and FN coatings decreased the COL1A expression to $<50 \%$ of that of cells on uncoated surfaces (Fig. 2). In contrast, collagen I coating had no significant effect on COL1A expression.

Culture of HCFs on C-ECM and collagen coatings expressed significantly more COL1A than HCFs cultured on intact C-ECM and collagen gels (Fig. 2). In contrast, NHLFs had mixed results. HCFs cultured on collagen coatings had a 1.38-fold higher COL1A expression than HCFs cultured on collagen gels $(1.07$ vs. $0.45, p<0.01)$. HCFs cultured on CECM2 coatings had a twofold higher COL1A expression than HCFs cultured on CECM2 intact samples (0.30 vs. $0.10, p<0.01)$.

Similarly, NHLFs cultured on collagen coatings had a $100 \%$ higher COL1A expression than NHLFs cultured on collagen gels $(1.03$ vs. $0.50, p<0.01)$. However, NHLFs cultured on CECM3 coatings showed the opposite trend and had $63 \%$ lower COL1A expression than NHLFs cultured on CECM3 intact samples $(0.30$ vs. $0.82, p<0.01)$. Culture of NHLFs on CECM2 coatings and CECM2 intact samples did not show a significant difference in COL1A expression.

For the cells treated with TGF $\beta$ as a positive control, HCF COL1A expression increased by 1.15 -fold and NHLF COL1A expression increased by $\sim 15$-fold. For the cells
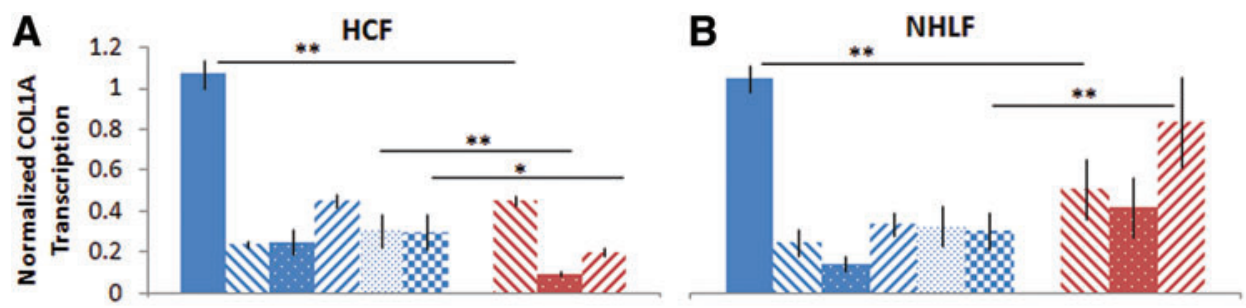

coll coat

N F coat

- LECM1 coat

" CECM1 coat

CECM2 coat

C

HCF

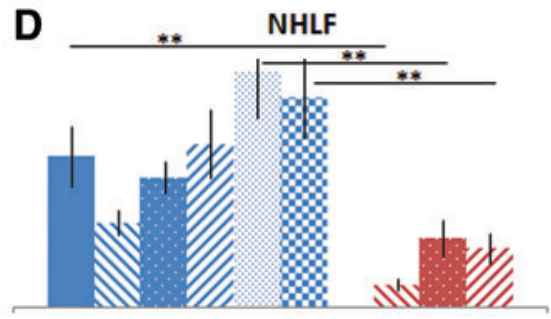

$\%$ CECM3 coat

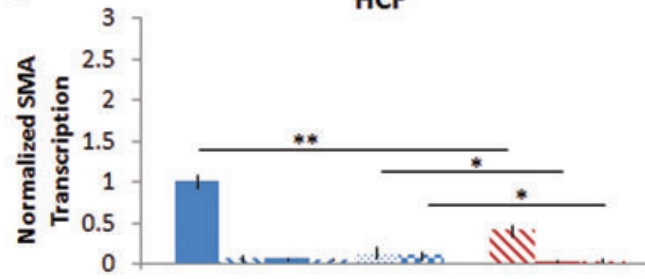

scollgel

a CECM2 intact

\% CECM3 intact

FIG. 2. COL1A and alpha-smooth muscle actin ( $\alpha$-SMA) RNA content of (A, C) human cardiac fibroblasts (HCFs) and (B, D) normal human lung fibroblasts (NHLFs) cultured on cardiac extracellular matrix (ECM), lung ECM, and individual ECM components for $48 \mathrm{~h}$, quantified by reverse transcription-quantitative polymerase chain reaction and normalized to expression of untreated fibroblasts (coll, type 1 collagen; FN, fibronectin; LECM1, lung ECM; CECM1, CECM2, and CECM3, cardiac ECM derived from three different conditions-see text for details). *Statistically significant differences between conditions $(p<0.05)$, **statistically significant differences between conditions $(p<0.01)$. $N=3$ for each gene. Error bars represent mean \pm standard deviation (SD). Color images available online at www.liebertpub.com/tea 
treated with TNF $\alpha$ as a negative control, HCF COL1A expression decreased by $36 \%$ and NHLF COL1A expression decreased by $29 \%$ (data not shown). These changes in expression agree with other published findings describing the effects of TGF $\beta$ and TNF $\alpha$ on collagen production. ${ }^{21-24}$

\section{aSMA RNA content}

Increased fibroblast contractility is another phenotypic feature of a myofibroblast, characterized by increased $\alpha \mathrm{SMA}$ expression. We measured $\alpha \mathrm{SMA}$ expression of HCFs and NHLFs cultured on cardiac ECM, lung ECM, and individual ECM components for $48 \mathrm{~h}$. The most striking result was the contrast in response between the HCFs and NHLFs. Culture of HCFs on ECM and FN coatings decreased $\alpha \mathrm{SMA}$ expression to $<15 \%$ of that of untreated HCFs, while collagen coatings had no significant effect on $\alpha$ SMA expression of HCFs (Fig. 2). In contrast, NHLFs cultured on ECM and collagen coatings increased $\alpha$ SMA expression by $59-182 \%$, while the FN coating had no significant effect on $\alpha \mathrm{SMA}$ expression. Both HCFs and NHLFs expressed significantly more $\alpha$ SMA when cultured on coatings compared to intact C-ECM and collagen gels (Fig. 2)

For the cells treated with TGF $\beta$ as a positive control, $\mathrm{HCF}$ $\alpha$ SMA expression increased by $71 \%$ and NHLF $\alpha$ SMA expression increased by $\sim 29$-fold. For the cells treated with $\mathrm{TNF} \alpha$ as a negative control, HCF $\alpha \mathrm{SMA}$ expression decreased by $36 \%$ and NHLF $\alpha$ SMA expression decreased by $28 \%$ (data not shown). These changes in expression agree with other published findings describing the effects of TGF $\beta$ and $\mathrm{TNF} \alpha$ on $\alpha \mathrm{SMA}$ production. ${ }^{25-27}$

\section{Cell proliferation and migration}

Tissue regeneration requires coordinated cell proliferation and migration, a key property of myofibroblasts. However, reports have shown that contraction and proliferation can be differentially exhibited in myofibroblasts under certain conditions. $^{28}$ We quantified cell proliferation and used a wound scrape assay to assess migration of fibroblasts cultured on LECM1 and CECM1. NHLFs cultured on LECM1 had a higher number of actively replicating cells compared to HCFs cultured on CECM1 ( $30 \%$ vs. $18 \%, p<0.01)$. A scratch-wound assay was then performed on NHLFs and HCFs under similar conditions, which demonstrated enhanced cell migration of the NHLFs (Fig. 3).

\section{$\alpha / \beta$ integrins}

Integrins transmit signals from the ECM to regulate the expression of intracellular contractile proteins, such as $\mathrm{SMA}$, as well as extracellular proteins, such as collagen. To determine the impact that specific decellularized matrix features have on fibroblast function and integrin signaling, we quantified integrin expression of fibroblasts cultured on ECM and its subcomponents. We found that the choice of ECM coating did not impact integrin expression, but that significant difference in the expression of integrin $\beta_{3}$ and $\beta_{4}$ existed between lung and cardiac fibroblasts.

HCFs expressed significantly different levels of $\alpha 4, \alpha 5$, $\alpha \mathrm{v}, \beta 1$, and $\beta 4$ levels when cultured on collagen, FN, LECM, or C-ECM coatings (Fig. 4). There was no consistent trend in the differences among the coatings. The most

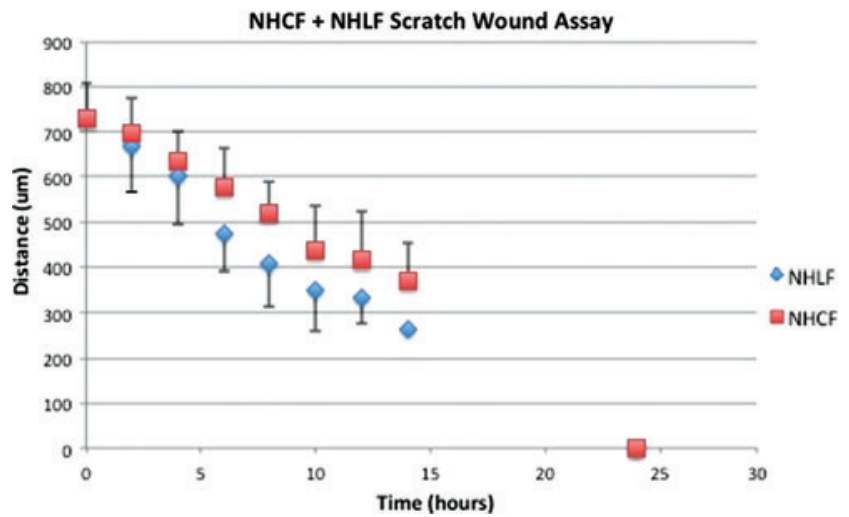

FIG. 3. Scratch wounds were applied to NHLF monolayers cultured on lung ECM and HCF monolayers cultured on cardiac ECM. Three distances of space were measured in the scratch of each well for 10 time points. Color images available online at www.liebertpub.com/tea

marked difference was a reduced expression of $\alpha_{4}$ and $\beta 4$ integrin on FN (Fig. 4). NHLFs expressed significantly different levels of $\alpha 1$ and $\alpha 3$, although again, there was no consistent trend in the differences.

The most striking observation was the different patterns of expression of the $\beta$ integrins between the NHLFs and HCFs. Both NHLFs and HCFs expressed low levels of $\beta_{2}$ and $\beta_{6}$; however, their expression of $\beta_{3}$ and $\beta_{4}$ was markedly different. While NHLFs expressed very low levels of $\beta_{3}$ and $\beta_{4}$ integrins (mean \pm standard deviation of $0.05 \pm 0.03$ and $0.04 \pm 0.02$, respectively), HCFs showed a significantly higher $(\sim 6$-fold) expression of these integrins across all of the coatings $(0.33 \pm 0.05$ and $0.27 \pm 0.16$, respectively).

Since the expression of $\beta_{3}$ and $\beta_{4}$ was markedly different between NHLFs and HCFs, as well as the expression of $\alpha$ SMA, we sought to determine whether there was a link. NHLFs and HCFs were treated with either anti- $\beta 3$-integrin or anti- $\beta 4$-integrin and then cultured on ECM and its subcomponents. We found that inhibition of the $\beta_{3}$ integrin significantly increased $\alpha \mathrm{SMA}$ expression of HCFs, suggesting that $\beta_{3}$ integrin may act to suppress SMA expression. Inhibition of the $\beta_{3}$ integrin did not significantly impact COL1A expression in HCFs and NHLFs, nor did inhibition impact $\alpha$ SMA expression in NHLFs (data not shown). In contrast, inhibition of the $\beta_{3}$ integrin dramatically increased $\alpha$ SMA expression of HCFs cultured on FN (16-fold) and ECM (20- to 26-fold) (Fig. 5). Inhibition of the $\beta_{4}$ integrin had no significant effect on COL1A and aSMA expression in either HCFs or NHLFs.

$\alpha$ SMA staining revealed increased levels of $\alpha$ SMA proteins in untreated NHLFs compared to untreated HCFs (75.82\% $\alpha$ SMA-positive cells compared to $61.9 \%$, Fig. 6). Inhibition of the $\beta_{3}$ integrin in HCFs cultured on CECM2 coatings resulted in a significant increase in $\alpha$ SMA compared to noninhibited HCFs $(86.67 \%$ aSMA-positive cells compared to $69.05 \%$ ). Inhibition of $\beta_{3}$ integrin, which we found to be expressed at much higher levels in HCFs than NHLFs, dramatically increased $\alpha$ SMA expression of HCFs. This suggested that differential expression of $\alpha \mathrm{SMA}$ by the lung and cardiac fibroblasts might be due to differences in the expression of the $\beta_{3}$ integrin. 

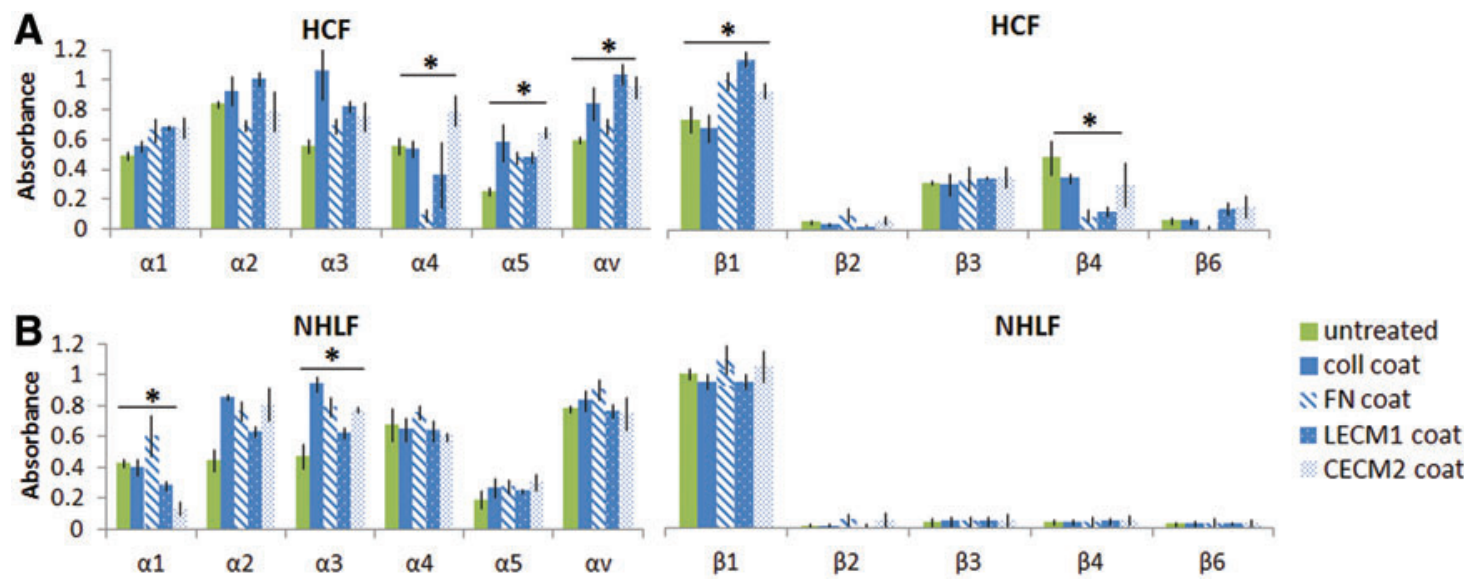

FIG. 4. $\alpha / \beta$ integrin expression of (A) HCFs and (B) NHLFs cultured on cardiac ECM, lung ECM, and individual ECM components (coll, type 1 collagen; FN, fibronectin; LECM1, lung ECM; CECM2, cardiac ECM derived from second condition-see text for details). *The set of conditions are statistically different from each other as shown by analysis of variance (ANOVA, $p<0.05$ ). Error bars represent mean \pm SD. Color images available online at www.liebertpub.com/tea

\section{Discussion}

Whole organ decellularization is a rapidly developing field that offers an instructive ECM that may aid in the development of engineered tissues. However, decellularization impacts the structural properties and protein composition of the ECM, ${ }^{1}$ and the organ-specific fibroblast cell response to the decellularized matrix has not been described. Since the lung and heart are two organs that have received significant attention in the literature describing decellular- ized organs, ${ }^{3,4,6,29}$ we determined the response of lung and cardiac fibroblasts to a series of different substrates, including organ-specific decellularized ECM and their specific subcomponents.

Our results demonstrate that cell source (as opposed to the organ-specific ECM) is a primary determinant impacting the fibroblast phenotype (i.e., myofibroblast). In particular, $\beta_{3}$ integrin expression is significantly higher in HCFs and this directly inhibits $\alpha$ SMA expression, and thus the myofibroblast phenotype.
A
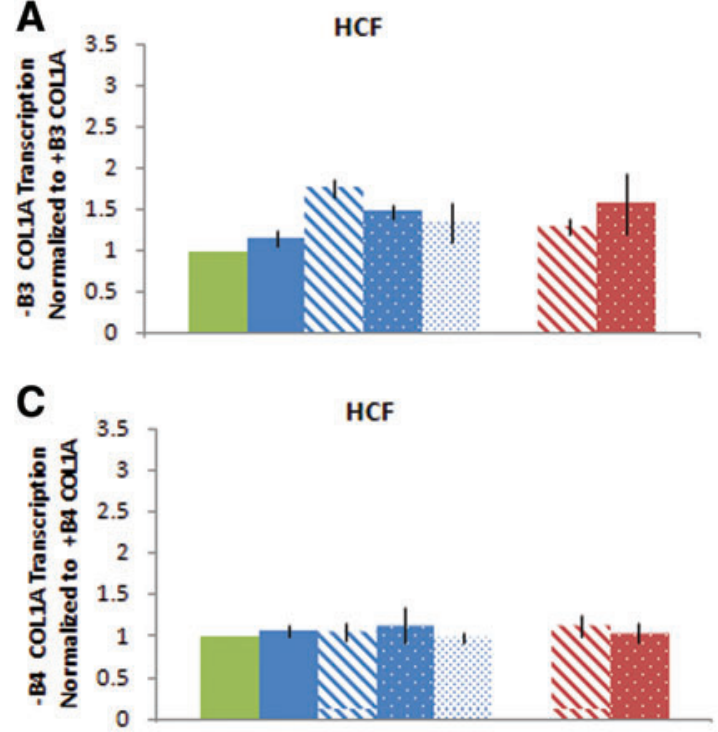

B
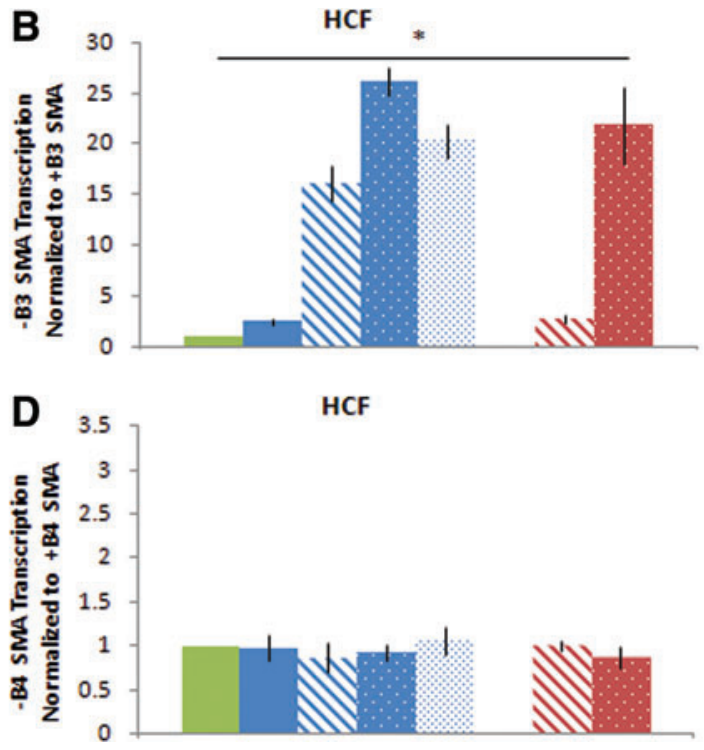

- untreated

a coll coat

N FN coat

롤 LECM1 coat

CECM2 coat

$\checkmark$ coll gel

CECM2 intact

FIG. 5. (A) COL1A and (B) $\alpha$-SMA RNA content of HCFs cultured on cardiac ECM, lung ECM, and individual ECM components with a 48-h incubation with $\beta_{3}$ integrin blocking antibodies normalized to RNA content of NHLFs and HCFs without integrin blocking antibodies. (C) COL1A and (D) $\alpha$-SMA RNA content of HCFs cultured on cardiac ECM, lung ECM, and individual ECM components with a 48-h incubation with $\beta_{4}$ integrin blocking antibodies normalized to RNA content of NHLFs and HCFs without integrin blocking antibodies $(+\mathrm{B} 3$, with blocking antibody to integrin $\beta 3$; $-\mathrm{B} 3$, without blocking antibody to integrin $\beta 3 ;+\mathrm{B} 4$, with blocking antibody to integrin $\beta 4 ;-\mathrm{B} 4$, without blocking antibody to integrin $\beta 4$; coll, type 1 collagen; FN, fibronectin; LECM1, lung ECM; CECM2, cardiac ECM derived from second condition-see text for details). *The set of conditions is statistically different from each other as shown by ANOVA $(p<0.05)$. Error bars represent mean $\pm S D$. Color images available online at www.liebertpub.com/tea 
HCF
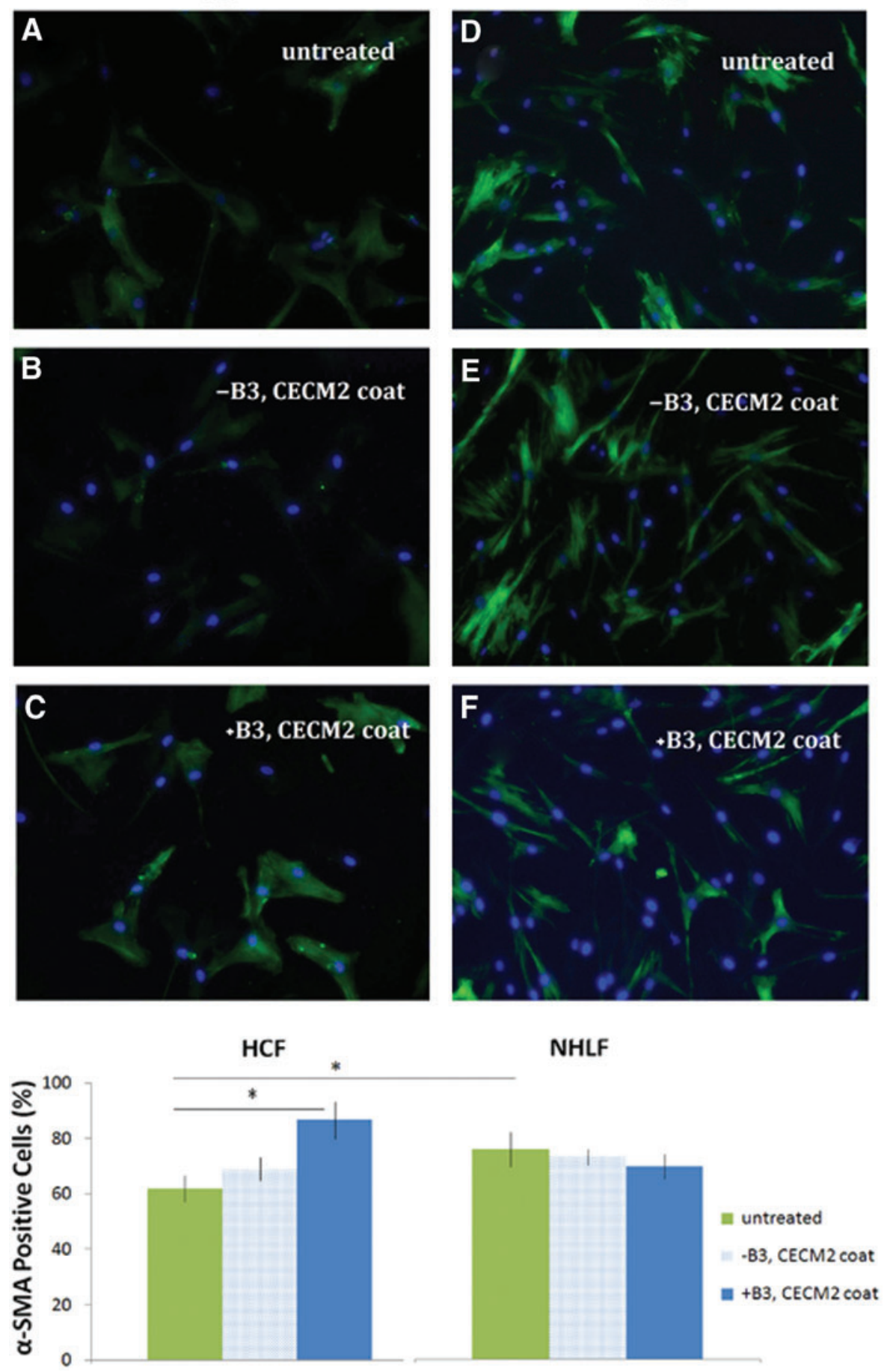

FIG. 6. Detection of $\alpha$-SMA (green) in HCFs (A-C) and NHLFs (D-F) with and without a 48-h incubation with $\beta_{3}$ integrin blocking antibodies $(+\mathrm{B} 3$, with blocking antibody to integrin $\beta 3$; $-\mathrm{B} 3$, without blocking antibody to integrin 33 ; CECM2, cardiac ECM derived from second conditionsee text for details). *Statistically significant differences between conditions $(p<0.05)$. Color images available online at www.liebertpub .com/tea

\section{Differential response of human cardiac and lung} fibroblasts to decellularized ECM

NHLFs cultured on ECM and FN coatings expressed significantly more $\alpha$ SMA than HCFs cultured under the same conditions (Fig. 2). The higher expression of $\alpha$ SMA in NHLFs typifies a myofibroblast or activated phenotype, as described by other studies using NHLFs. ${ }^{30,31}$ This suggests that NHLFs will be more contractile and more likely to deposit ECM proteins than HCFs. ${ }^{32-34}$ Our scratch-wound assay revealed that the NHLFs cultured on the lung ECM migrate faster than the HCFs cultured on cardiac ECM, which agrees with the higher expression of $\alpha$ SMA seen in NHLFs. In addition to this increased motility, NHLFs exhibited a higher percentage of proliferating cells when compared to HCFs. It is likely that the similar fibroblast response to cardiac and lung ECM can be attributed to the similarities in the matrix composition.

SDS-PAGE revealed similar banding patterns between cardiac and lung ECM, while mass spectrometry demonstrated significant overlap in the protein composition in both ECMs. Several types of cells have been used to recellularize 
the ECM, with varying levels of success, including smooth muscle, endothelial, and fibroblast. ${ }^{6,29,35}$ However, few comparative studies have been performed to determine the potential benefits of using tissue-specific cells to recellularize the ECM. In this study, we see that organ-specific stromal cells have intrinsic differences in protein expression (i.e., $\alpha$ SMA) that may profoundly influence cell response during recellularization.

\section{Differential integrin expression of cardiac and lung fibroblasts}

We hypothesized that the differential expression of $\mathrm{SMA}$ by the lung and cardiac fibroblasts might be due to differences in the expression of cell surface integrins, as these proteins interact directly with ECM proteins to impact protein expression and cell function such as migration. ${ }^{8,9,36}$ In general, we found that the choice of ECM coating did not impact integrin expression; rather, we found significant differences in the expression of integrin $\beta_{3}$ and $\beta_{4}$ between the lung and cardiac fibroblast (Fig. 4).

Integrins are membrane-bound proteins that mediate cellcell and cell-ECM interactions. They play a critical role in ECM maintenance and remodeling by transmitting signals from the ECM to regulate cell function. The $\beta_{3}$ subunit, most commonly associated with $\alpha_{\mathrm{v}}$, has been shown to regulate wound healing and re-epithelialization. ${ }^{9}$ Expression of $\alpha_{v} \beta_{3}$ (a receptor for vitronectin and other ECM molecules) is elevated on several cell types involved in wound healing, including dermal fibroblasts. $\alpha_{\mathrm{v}} \beta_{3}$ has been shown to regulate the fibroblast phenotype, TGF $\beta$ receptor expression, and downstream TGF $\beta$ signaling. $\beta_{4}$ integrin subunits are usually found in $\alpha_{6} \beta_{4}$, an integrin laminin receptor. $\alpha_{6} \beta_{4}$ has been reported to play important roles in epithelial cell migration by mediating traction forces and signaling molecules.

\section{Expression of integrin $\beta_{3}$ inhibits $\alpha$ SMA expression}

Higher levels of $\beta_{3}$ and $\beta_{4}$ integrins in HCFs, combined with their role in wound healing and cell migration, suggested that they play a role in suppressing the expression of aSMA. Functional blocking antibodies against $\beta_{3}$ integrins, but not $\beta_{4}$, in HCFs significantly increased $\alpha \mathrm{SMA}$ expression (Fig. 5). Staining confirmed a significantly higher aSMA expression in HCFs after blocking the $\beta_{3}$ integrin. $\alpha$ SMA has also been shown to be a definitive marker of the myofibroblast phenotype. ${ }^{34,37}$ Therefore, this result demonstrates that $\beta_{3}$ expression can regulate $\alpha \mathrm{SMA}$ expression, and thus the myofibroblast phenotype. In addition, this result suggests that tissue-specific fibroblasts may play an important role in organ-specific recellularization strategies.

Fibroblast expression of COL1A and $\alpha$ SMA has previously been shown to be strongly associated, resulting from myofibroblast differentiation and the fibrotic response. ${ }^{34,38,39}$ However, we did not observe a correlation between COL1A and $\alpha$ SMA in our study (Fig. 2). In particular, COL1A expression was generally not higher in NHLFs cultured on coatings. This may have been due to the timescale of our experiments, since we measured COL1A and $\alpha$ SMA expression $48 \mathrm{~h}$ after seeding the fibroblasts. Longer time points may result in elevated COL1A.
There may have also been other factors mediating COL1A expression beyond mechanical properties, such as structural features of the ECM. We previously demonstrated that different decellularization conditions can produce ECM with significantly different collagen and elastin structures. ${ }^{1}$ These structural features may play a role in regulating COL1A and $\alpha$ SMA expression.

\section{Fibroblast response to intact ECM versus ECM coatings}

HCFs and NHLFs cultured on the decellularized ECM and collagen coatings resulted in increased $\alpha$ SMA expression, when compared to the intact decellularized ECM and collagen gels (Fig. 2). Higher expression of $\alpha \mathrm{SMA}$ in fibroblasts on coatings represents a myofibroblast phenotype and an increased fibrotic response, which may be due to the difference in substrate stiffness.

Previous studies have shown that the mechanical properties of a cell's microenvironment have as significant an impact on cell morphology and function as soluble factors and cell-cell contact. ${ }^{40,41}$ Cells cultured on stiff substrates upregulate the expression of integrins, ${ }^{42}$ assemble actin stress fibers, ${ }^{43}$ and exhibit a more spread phenotype. ${ }^{40}$ Cells cultured on coated flasks may be responding to the stiffness of the polystyrene. Our findings are consistent with these previous reports. These findings suggest that HCFs and NHLFs will express less aSMA if introduced into decellularized ECM that is mechanically softer than intact tissue.

In addition to bulk mechanical stiffness, there are other differences between the coatings and the intact ECM. Pepsin digestion of decellularized ECM to form coatings may alter protein structure and, thus, the moieties that are presented to the cell. ${ }^{44,45}$ Furthermore, selective adsorption of ECM proteins in coatings may change the composition and conformation of those proteins. ${ }^{46,47}$

Adsorption of collagen on polystyrene has been shown to result in a different molecular organization and strand size, depending on the time interval and concentration of the solution, ${ }^{48,49}$ and the elastic modulus of individual collagen fibrils has been reported to change with the fibril diameter. ${ }^{50}$ Thus, the difference in size and orientation of collagen fibrils between collagen coatings and intact ECM may result in different substrate nanomechanics. Collagen nanomechanical properties have been shown to affect contractility and spreading of human megakaryocytes, ${ }^{51}$ but it is unclear what impact these properties may have on fibroblast function.

\section{Conclusion}

Whole organ decellularization potentially offers an instructive matrix for the creation of engineered tissues. Studies have shown that ECM can influence chemotaxis, direct cell differentiation, and induce constructive host tissue remodeling. Furthermore, significant structural differences exist between intact ECM and ECM coatings. Our results demonstrate that the source of fibroblast can significantly impact phenotype, and that the differential response is linked to $\beta_{3}$ integrin expression. In addition, the fibroblast response to intact ECM differs from the fibroblast response to ECM coatings. We conclude that the fibroblast source, $\beta_{3}$ integrin expression, and ECM structure play important roles 
in controlling the fibroblast phenotype, and thus may impact stromal cell function during recellularization.

\section{Acknowledgments}

This work has been supported, in part, by grants from the National Institutes of Health, UH2 TR000481 (S.C.G.) and 1R01HL113468 (K.L.C.). We would like to recognize Mr. Earl Steward for assistance in procuring the porcine hearts. We would also like to recognize Ryan Hill and Monika Dzieciatkowska for collecting the mass spectrometry data and writing the mass spectrometry methods.

\section{Disclosure Statement}

Dr. Christman is co-founder, board member, and holds equity interest in Ventrix, Inc. Other authors have no competing financial interests.

\section{References}

1. Merna, N., Robertson, C., La, A., and George, S.C. Optical imaging predicts mechanical properties during decellularization of cardiac tissue. Tissue Eng Part C Methods 19, 802, 2013.

2. Puck, T.T., Cieciura, S.J., and Fisher, H.W. Clonal growth in vitro of human cells with fibroblastic morphology; comparison of growth and genetic characteristics of single epithelioid and fibroblast-like cells from a variety of human organs. J Exp Med 106, 145, 1957.

3. Ott, H.C., Matthiesen, T.S., Goh, S.K., Black, L.D., Kren, S.M., Netoff, T.I., and Taylor, D.A. Perfusion-decellularized matrix: using nature's platform to engineer a bioartificial heart. Nat Med 14, 213, 2008.

4. Petersen, T.H., Calle, E.A., Zhao, L., Lee, E.J., Gui, L., Raredon, M.B., Gavrilov, K., Yi, T., Zhuang, Z.W., Breuer, C., Herzog, E., and Niklason, L.E. Tissue-engineered lungs for in vivo implantation. Science 329, 538, 2010.

5. Wainwright, J.M., Czajka, C.A., Patel, U.B., Freytes, D.O., Tobita, K., Gilbert, T.W., and Badylak, S.F. Preparation of cardiac extracellular matrix from an intact porcine heart. Tissue Eng Part C Methods 16, 525, 2010.

6. Eitan, Y., Sarig, U., Dahan, N., and Machluf, M. Acellular cardiac extracellular matrix as a scaffold for tissue engineering: in vitro cell support, remodeling, and biocompatibility. Tissue Eng Part C Methods 16, 671, 2010.

7. Bishop, J.E., and Lindahl, G. Regulation of cardiovascular collagen synthesis by mechanical load. Cardiovasc Res $\mathbf{4 2}$, 27, 1999.

8. Scaffidi, A.K., Moodley, Y.P., Weichselbaum, M., Thompson, P.J., and Knight, D.A. Regulation of human lung fibroblast phenotype and function by vitronectin and vitronectin integrins. J Cell Sci 114, 3507, 2001.

9. Reynolds, L.E., Conti, F.J., Lucas, M., Grose, R., Robinson, S., Stone, M., Saunders, G., Dickson, C., Hynes, R.O., LacyHulbert, A., and Hodivala-Dilke, K. Accelerated reepithelialization in beta3-integrin-deficient- mice is associated with enhanced TGF-beta1 signaling. Nat Med 11, 167, 2005.

10. DeQuach, J.A., Mezzano, V., Miglani, A., Lange, S., Keller, G.M., Sheikh, F., and Christman, K.L. Simple and high yielding method for preparing tissue specific extracellular matrix coatings for cell culture. PLoS One 5, e13039, 2010.

11. Zhang, Y., He, Y., Bharadwaj, S., Hammam, N., Carnagey, K., Myers, R., Atala, A., and Van Dyke, M. Tissue-specific extracellular matrix coatings for the promotion of cell proliferation and maintenance of cell phenotype. Biomaterials 30, 4021, 2009.

12. Reilly, G.C., and Engler, A.J. Intrinsic extracellular matrix properties regulate stem cell differentiation. J Biomech $\mathbf{4 3}$, 55, 2009.

13. Wang, H.J., Pieper, J., Schotel, R., van Blitterswijk, C.A., and Lamme, E.N. Stimulation of skin repair is dependent on fibroblast source and presence of extracellular matrix. Tissue Eng 10, 1054, 2004.

14. Crapo, P.M., Gilbert, T.W., and Badylak, S.F. An overview of tissue and whole organ decellularization processes. Biomaterials 32, 3233, 2011.

15. Badylak, S.F., Taylor, D., and Uygun, K. Whole-organ tissue engineering: decellularization and recellularization of three-dimensional matrix scaffolds. Annu Rev Biomed Eng 13, 27, 2011.

16. Freytes, D.O., Martin, J., Velankar, S.S., Lee, A.S., and Badylak, S.F. Preparation and rheological characterization of a gel form of the porcine urinary bladder matrix. Biomaterials 29, 1630, 2008.

17. LeRoy, E.C., Trojanowska, M.I., and Smith, E.A. Cytokines and human fibrosis. Eur Cytokine Netw 1, 215, 1990.

18. Hill, A.G. Initiators and propagators of the metabolic response to injury. World J Surg 24, 624, 2000.

19. Hatamochi, A., Mori, K., and Ueki, H. Role of cytokines in controlling connective tissue gene expression. Arch Dermatol Res 287, 115, 1994.

20. Arold, S.P., Malavia, N., and George, S.C. Mechanical compression attenuates normal human bronchial epithelial wound healing. Respir Res 10, 9, 2009.

21. Raghu, G., Masta, S., Meyers, D., and Narayanan, A.S. Collagen synthesis by normal and fibrotic human lung fibroblasts and the effect of transforming growth factor-beta. Am Rev Respir Dis 140, 95, 1989.

22. Elias, J.A., Freundlich, B., Adams, S., and Rosenbloom, J. Regulation of human lung fibroblast collagen production by recombinant interleukin-1, tumor necrosis factor, and interferon-gamma. Ann N Y Acad Sci 580, 233, 1990.

23. Lijnen, P.J., Petrov, V.V., and Fagard, R.H. Collagen production in cardiac fibroblasts during inhibition of angiotensinconverting enzyme and aminopeptidases. J Hypertens 22, 209, 2004.

24. Siwik, D.A., Chang, D.L., and Colucci, W.S. Interleukin1 beta and tumor necrosis factor-alpha decrease collagen synthesis and increase matrix metalloproteinase activity in cardiac fibroblasts in vitro. Circ Res 86, 1259, 2000.

25. Zhang, H.Y., Gharaee-Kermani, M., Zhang, K., Karmiol, S., and Phan, S.H. Lung fibroblast alpha-smooth muscle actin expression and contractile phenotype in bleomycininduced pulmonary fibrosis. Am J Pathol 148, 527, 1996.

26. Mariani, T.J., Arikan, M.C., and Pierce, R.A. Fibroblast tropoelastin and alpha-smooth-muscle actin expression are repressed by particulate-activated macrophage-derived tumor necrosis factor-alpha in experimental silicosis. Am J Respir Cell Mol Biol 21, 185, 1999.

27. Lijnen, P., and Petrov, V. Transforming growth factor-beta 1 -induced collagen production in cultures of cardiac fibroblasts is the result of the appearance of myofibroblasts. Methods Find Exp Clin Pharmacol 24, 333, 2002.

28. Grotendorst, G.R., Rahmanie, H., and Duncan, M.R. Combinatorial signaling pathways determine fibroblast proliferation and myofibroblast differentiation. FASEB J 18, 469, 2004. 
29. Ott, H.C., Clippinger, B., Conrad, C., Schuetz, C., Pomerantseva, I., Ikonomou, L., Kotton, D., and Vacanti, J.P. Regeneration and orthotopic transplantation of a bioartificial lung. Nat Med 16, 927, 2010.

30. Luo, F., Zhuang, Y., Sides, M.D., Sanchez, C.G., Shan, B., White, E.S., and Lasky, J.A. Arsenic trioxide inhibits transforming growth factor-beta1-induced fibroblast to myofibroblast differentiation in vitro and bleomycin induced lung fibrosis in vivo. Respir Res 15, 51, 2014.

31. Sobel, K., Menyhart, K., Killer, N., Renault, B., Bauer, Y., Studer, R., Steiner, B., Bolli, M.H., Nayler, O., and Gatfield, J. Sphingosine 1-phosphate (S1P) receptor agonists mediate pro-fibrotic responses in normal human lung fibroblasts via S1P2 and S1P3 receptors and Smadindependent signaling. J Biol Chem 288, 14839, 2013.

32. van den Borne, S.W., Diez, J., Blankesteijn, W.M., Verjans, J., Hofstra, L., and Narula, J. Myocardial remodeling after infarction: the role of myofibroblasts. Nat Rev Cardiol 7, 30, 2010.

33. Desmouliere, A., Chaponnier, C., and Gabbiani, G. Tissue repair, contraction, and the myofibroblast. Wound Repair Regen 13, 7, 2005.

34. Gabbiani, G. The myofibroblast in wound healing and fibrocontractive diseases. J Pathol 200, 500, 2003.

35. Kim, B.S., Choi, J.S., Kim, J.D., Choi, Y.C., and Cho, Y.W. Recellularization of decellularized human adipose-tissuederived extracellular matrix sheets with other human cell types. Cell Tissue Res 348, 559, 2012.

36. Margadant, C., and Sonnenberg, A. Integrin-TGF-beta crosstalk in fibrosis, cancer and wound healing. EMBO Rep 11, 97, 2010.

37. Hinz, B., Phan, S.H., Thannickal, V.J., Galli, A., Bochaton-Piallat, M.L., and Gabbiani, G. The myofibroblast: one function, multiple origins. Am J Pathol 170, 1807, 2007.

38. Burgess, H.A., Daugherty, L.E., Thatcher, T.H., Lakatos, H.F., Ray, D.M., Redonnet, M., Phipps, R.P., and Sime, P.J. PPARgamma agonists inhibit TGF-beta induced pulmonary myofibroblast differentiation and collagen production: implications for therapy of lung fibrosis. Am J Physiol Lung Cell Mol Physiol 288, L1146, 2005.

39. Phan, S.H. The myofibroblast in pulmonary fibrosis. Chest 122, 286S, 2002.

40. Pelham, R.J., Jr., and Wang, Y. Cell locomotion and focal adhesions are regulated by substrate flexibility. Proc Natl Acad Sci U S A 94, 13661, 1997.

41. Solon, J., Levental, I., Sengupta, K., Georges, P.C., and Janmey, P.A. Fibroblast adaptation and stiffness matching to soft elastic substrates. Biophys J 93, 4453, 2007.
42. Yeung, T., Georges, P.C., Flanagan, L.A., Marg, B., Ortiz, M., Funaki, M., Zahir, N., Ming, W., Weaver, V., and Janmey, P.A. Effects of substrate stiffness on cell morphology, cytoskeletal structure, and adhesion. Cell Motil Cytoskeleton 60, 24, 2005.

43. Georges, P.C., and Janmey, P.A. Cell type-specific response to growth on soft materials. J Appl Physiol 98, 1547, 2005.

44. Nalinanon, S., Benjakul, S., Visessanguan, W., and Kishimura, H. Use of pepsin for collagen extraction from the skin of bigeye snapper (Priacanthus tayenus). Food Chem 104, 593, 2007.

45. Miller, E.J. Structural studies on cartilage collagen employing limited cleavage and solubilization with pepsin. Biochemistry 11, 4903, 1972.

46. Wilson, C.J., Clegg, R.E., Leavesley, D.I., and Pearcy, M.J. Mediation of biomaterial-cell interactions by adsorbed proteins: a review. Tissue Eng 11, 1, 2005.

47. Absolom, D.R., Zingg, W., and Neumann, A.W. Protein adsorption to polymer particles: role of surface properties. J Biomed Mater Res 21, 161, 1987.

48. Pamula, E., De Cupere, V., Dufrene, Y.F., and Rouxhet, P.G. Nanoscale organization of adsorbed collagen: influence of substrate hydrophobicity and adsorption time. J Colloid Interface Sci 271, 80, 2004.

49. Xu, S., Liu, A., Chen, Q., Lv, M., Yonese, M., and Liu, H. Self-assembly nano-structure of type I collagen adsorbed on Gemini surfactant LB monolayers. Colloids Surf B Biointerfaces 70, 124, 2009.

50. Chung, K.H., Bhadriraju, K., Spurlin, T.A., Cook, R.F., and Plant, A.L. Nanomechanical properties of thin films of type I collagen fibrils. Langmuir 26, 3629, 2009.

51. Malara, A., Gruppi, C., Pallotta, I., Spedden, E., Tenni, R., Raspanti, M., Kaplan, D., Tira, M.E., Staii, C., and Balduini, A. Extracellular matrix structure and nano-mechanics determine megakaryocyte function. Blood 118, 4449, 2011.

Address correspondence to:

Steven C. George, $M D, P h D$

Department of Biomedical Engineering Washington University in St. Louis 1 Brookings Drive St. Louis, MO 63130

E-mail: scg@wustl.edu

Received: June 6, 2014 Accepted: April 27, 2015 Online Publication Date: June 2, 2015 